\title{
Landscape of somatic mutations in sporadic GH-secreting pituitary adenomas
}

\author{
Cristina L Ronchi ${ }^{1}$, Erika Peverelli ${ }^{2}$, Sabine Herterich ${ }^{3}$, Isabel Weigand" \\ Giovanna Mantovani ${ }^{2}$, Thomas Schwarzmayr ${ }^{4}$, Silviu Sbiera5 $^{5}$, Bruno Allolio', \\ Jürgen Honegger ${ }^{6}$, Silke Appenzeller ${ }^{5,7}$, Andrea G Lania ${ }^{8}, M_{a r t i n ~ R e i n c k e}{ }^{6}$, \\ Davide Calebiro ${ }^{9}$, Anna Spada ${ }^{2}$, Michael Buchfelder ${ }^{10}$, Joerg Flitsch ${ }^{11}$, \\ Tim M Strom ${ }^{4,12}$ and Martin Fassnacht ${ }^{1,5}$
}

\begin{abstract}
${ }^{1}$ Department of Internal Medicine I, Endocrine and Diabetes Unit, University Hospital, University of Wuerzburg, Oberduerrbacherstrasse 6, 97080 Wuerzburg, Germany, ${ }^{2}$ Endocrinology and Diabetology Unit, Department of Clinical Sciences and Community Health, University of Milan, Milan, Italy, ${ }^{3}$ Central Laboratory, University Hospital, University of Wuerzburg, Wuerzburg, Germany, ${ }^{4}$ Institute of Human Genetics, Helmholtz Zentrum Munich, Neuherberg, Germany, ${ }^{5}$ Comprehensive Cancer Center Mainfranken, University of Wuerzburg, Wuerzburg, Germany, ${ }^{6}$ Medizinische Klinik and Poliklinik IV, Ludwig-Maximilians University, Munich, Germany, ${ }^{7}$ Core Unit Systems Medicine, University of Wuerzburg, Wuerzburg, Germany, ${ }^{8}$ Endocrinology Unit, Department of Biomedical Sciences, Humanitas Research Hospital, Humanitas University, Rozzano, Milan, Italy, ${ }^{9}$ Institute of Pharmacology and Toxicology and Bioimaging Center, University of Wuerzburg, Wuerzburg, Germany, ${ }^{10}$ Department of Neurosurgery, University Hospital of Erlangen, Erlangen, Germany, ${ }^{11}$ Neurosurgery, University Hospital of Hamburg-Eppendorf, Hamburg, Germany and ${ }^{12}$ Institute of Human Genetics, Technische Universitaet Muenchen, Munich, Germany
\end{abstract}

\author{
Correspondence \\ should be addressed \\ to C L Ronchi \\ Email \\ Ronchi_c@ukw.de
}

\begin{abstract}
Context: Alterations in the CAMP signaling pathway are common in hormonally active endocrine tumors. Somatic mutations at GNAS are causative in 30-40\% of GH-secreting adenomas. Recently, mutations affecting the USP8 and PRKACA gene have been reported in ACTH-secreting pituitary adenomas and cortisol-secreting adrenocortical adenomas respectively. However, the pathogenesis of many $\mathrm{GH}$-secreting adenomas remains unclear.

Aim: Comprehensive genetic characterization of sporadic $\mathrm{GH}$-secreting adenomas and identification of new driver mutations. Design: Screening for somatic mutations was performed in $67 \mathrm{GH}$-secreting adenomas by targeted sequencing for GNAS, PRKACA, and USP8 mutations $(n=31)$ and next-generation exome sequencing $(n=36)$.

Results: By targeted sequencing, known activating mutations in GNAS were detected in five cases (16.1\%), while no somatic mutations were observed in both PRKACA and USP8. Whole-exome sequencing identified 132 protein-altering somatic mutations in 31/36 tumors with a median of three mutations per sample (range: 1-13). The only recurrent mutations have been observed in GNAS (31.4\% of cases). However, seven genes involved in cAMP signaling pathway were affected in 14 of 36 samples and eight samples harbored variants in genes involved in the calcium signaling or metabolism. At the enrichment analysis, several altered genes resulted to be associated with developmental processes. No significant correlation between genetic alterations and the clinical data was observed.

Conclusion: This study provides a comprehensive analysis of somatic mutations in a large series of GH-secreting adenomas. No novel recurrent genetic alterations have been observed, but the data suggest that beside cAMP pathway, calcium signaling might be involved in the pathogenesis of these tumors.

\section{Introduction}

Pituitary tumors represent $\sim 15 \%$ of all primary intracranial lesions. Growth hormone (GH)-secreting pituitary adenomas are the second most frequent type of hormone-producing pituitary tumors, after prolactinsecreting adenomas (1). Excessive secretion of GH causes gigantism during childhood and acromegaly in adults, (c) 2016 European Society of Endocrinology Printed in Great Britain
Published by Bioscientifica Ltd. 
with significant morbidity due to clinical complications involving cardiovascular, respiratory, and metabolic systems $(2,3)$.

The monoclonal origin of most pituitary adenomas indicates that these tumors derive from the replication of a single cell that acquired growth advantage. The latter has been suggested to result from genetic or epigenetic alterations, leading to activation of proto-oncogenes or inactivation of tumor suppressor genes $(4,5)$. However, despite intensive investigations, little is known about the genetic causes of pituitary adenomas. The only mutations identified to date in a significant proportion (30-40\%) of sporadic GH-secreting adenomas occur in the gene encoding the $\alpha$ subunit of the stimulatory G-protein $(G N A S)(6,7$, $8,9)$. These somatic activating mutations ( $g s p$ mutations), found in codon 201 and 227, prevent hydrolysis of GTP, leading to a constitutive activation of the cAMP pathway, which in somatotrophs and in other endocrine cells acts as a mitogenic signal $(10,11)$. In somatotrophs, the GNAS transcript is expressed mainly from the maternal allele, due to tissue-specific paternal imprinting $(12,13)$. Consistently, gsp mutations in sporadic GH-secreting adenomas are found on the maternal allele (14), and partial loss of this imprinting is present in tumors negative for $g s p$ mutations (15), further supporting the involvement of GNAS locus in pituitary tumorigenesis. So far, the screening for mutations in other G-protein subunits in pituitary tumors has given negative results $(16,17,18)$.

Genetic alterations in other genes involved in cAMP signaling have been identified as the cause of other endocrine tumors. A reduced expression and/or function of the protein kinase A (PKA) regulatory subunit type I $\alpha$ (PRKAR1A) due to loss-of-function mutations, leading to an abnormal cAMP pathway activation, causes GH-secreting pituitary adenomas in Carney complex, an autosomal dominant familial syndrome $(19,20)$. To date, mutations of PRKAR1A gene have been rarely found in sporadic pituitary tumors $(21,22)$, although a reduced PRKAR1A expression resulting from increased proteasomal degradation has been described in sporadic GH-secreting tumors (10). Reduced cAMP degradation caused by mutations in PDE11A and PDE8B, coding for members of the phosphodiesterase (PDE) family, have been involved in adrenocortical hyperplasia, adenomas, and cancer as well as in testicular germ cell tumors $(23,24)$. However, genetic variants of PDE11A4 contribute only marginally to the development of GH-secreting adenomas (25). Recently, mutations affecting the gene encoding the catalytic subunit $\alpha$ of the PKA (PRKACA) have been reported in a large proportion of cortisol-secreting adrenocortical adenomas $(26,27,28,29,30)$, resulting in an increased PKA activity (31). Nevertheless, no hot spot mutations of PRKACA have been identified in a large cohort of GH-secreting adenomas (32). Finally, a recurrent somatic mutation in the GPR101 gene, which encodes an orphan G-protein-coupled receptor (GPCR), has been recently reported in some adults with acromegaly (4\% of cases) (33).

In addition, epidermal growth factor receptor (EGFR) overexpression has been described in hormonally active pituitary adenomas (34) and role for epidermal growth factor (EGF) and its receptor in the development and/or progression of pituitary tumors has been hypothesized (35). Dominant mutations in the deubiquitinase USP8 gene that promote activation of EGFR signaling have been also found in adrenocorticotropin (ACTH)-secreting pituitary adenomas by exome sequencing (36). Finally, germline mutations of genes such as the aryl hydrocarbon receptor-interacting protein (AIP), the menin (MEN1), and the p27 (CDKN1B) have been reported in genetic syndromes associated with acromegaly (i.e., familialisolated pituitary adenoma and multiple endocrine neoplasia type 1 and 4) and in a low percentage of young acromegalic patients (37).

Recently, Valimäki et al. investigated a small group of 12 patients with GH-secreting adenomas by wholegenome sequencing and single nucleotide polymorphism (SNP) array and did not find any novel recurrent genetic alteration (38). Aim of the present study was to perform a comprehensive genetic characterization of a large series of GH-secreting adenomas to identify novel genetic alterations potentially involved in tumorigenesis and/or in clinical outcome. To this aim, we used both targeted direct sequencing of GNAS, PRKACA, and USP8 genes and nextgeneration exome sequencing.

\section{Subjects and methods}

\section{Tissue samples, patients, and clinical annotations}

Sporadic GH-secreting adenomas without familial or syndromic presentation were recruited in the present study. Accordingly, a total of 81 fresh frozen tumors were collected from four different participating European centers. If available, corresponding peripheral blood was also collected for the analysis. Inclusion criteria for participating in the study were a certified histological diagnosis of benign GH-secreting adenomas and available clinical data. The DNA was isolated as described previously (39). Qualitative and quantitative evaluation of the DNA was assessed by electrophoresis in a 1\% agarose gel and 
spectrophotometrically at $260 \mathrm{~nm}$ respectively. At the first screening, 14 tumor samples have been excluded due to insufficient DNA quality so that the final series included a total of $67 \mathrm{GH}$-secreting adenomas. Among them, the tumor samples were subdivided into two groups according to the availability of corresponding leukocyte DNA essential for next-generation whole-exome sequencing. Thus, 31 tumor samples underwent targeted direct sequencing for the analysis of selected genes (GNAS, PRKACA, and USP8) (Group 1), while the remaining 36 cases with corresponding leukocyte DNA were investigated by whole-exome sequencing (Group 2).

Clinical parameters, such as sex, age at diagnosis, date of surgery, tumor size, GH and IGF1 levels, presence of acromegaly-related complications, and follow-up data, were collected for all patients at the local centers. All the patients gave written informed consent, and the study was approved by the ethics committee at each participating institution.

\section{Targeted and whole-exome sequencing and data analysis}

For the targeted sequencing analysis, we focused on gene domains harboring alterations known or supposed biologically relevant in endocrine active tumors, i.e. known gain-of-function GNAS mutations (codon 201 and 227), mutations in the catalytic domain of the PRKACA (exon 7 and 8), and in the 14-3-3 binding domain and the microtubule-interacting and transport-domain (exons 1, 2, and 3) of the USP8, which is reported to be involved in regulating USP8 catalytic function. The primers used for the targeted direct sequencing were generated with the Program Primer3Plus (39).

The complete list of the primers is reported in the Supplementary Table 1 , see section on supplementary data given at the end of this article. In brief, PCR was performed on $1 \mu \mathrm{l}$ of diluted DNA ( $2 \mathrm{ng} / \mu \mathrm{l})$ in a final volume of $25 \mu \mathrm{l}$ containing $1.5 \mathrm{mM} \mathrm{MgCl}_{2}, 0.2 \mu \mathrm{M}$ of each primer, $200 \mu \mathrm{M}$ dNTPs and $1 \mathrm{U}$ Taq DNA polymerase. The reaction was started with an initial $95{ }^{\circ} \mathrm{C}$ denaturation step for $3 \mathrm{~min}$, followed by 30 cycles of denaturation at $93{ }^{\circ} \mathrm{C}(20 \mathrm{~s})$, annealing at $58{ }^{\circ} \mathrm{C}(30 \mathrm{~s})$ and elongation at $72{ }^{\circ} \mathrm{C}(1 \mathrm{~min})$. Direct sequencing of PCR products was performed using the QuickStart cycle sequencing kit (ABSciex Four Valley drive Concord, Ontario, Canada) on a CEQ8000 DNA analyzer (ABSciex).

For the next-generation sequencing, exomes were enriched in solution and indexed with the use of the SureSelect XT human all exon $50 \mathrm{Mb}$ kit, version 5
(Agilent Technologies, Santa Clara, CA, USA). Sequencing was performed as paired-end reads of $100 \mathrm{bp}$ on a HiSeq2500 systems (Illumina, San Diego, CA, USA) generating $8-14 \mathrm{~Gb}$ of sequence and an average depth of coverage between $110 \times$ and $170 \times$ on target regions. More than $95 \%$ of the target regions were covered 20 times or more. Pools of 12 indexed libraries were sequenced on four lanes. Image analysis and base calling were performed with the use of real-time analysis software (Illumina). Reads were aligned against the human assembly hg19 (GRCh37) using the Burrows-Wheeler Aligner tool (BWA $\mathrm{v}$ 0.7.5a). Variant detection was done as described earlier (26).

Somatic variants have been evaluated by Polymorphism Phenotyping v2 tool (PolyPhen-2) (40) and scale invariant feature transform (SIFT) algorithm (http://sift.jcvi.org/index.html) (41). An unsupervised complete linkage clustering including the most relevant somatic mutations was performed by the Hamming distance as a similarity metric. The Gene Set Enrichment Analysis (GSEA) software was used for the gene enrichment and the functional annotation (Broad Institute, MSigDB database v5.0; http://software.broadinstitute.org/ gsea) (42). A canonical pathway analysis (1330 gene set) and a gene family analysis were also performed with the same software.

\section{Statistical analysis}

Median, interquartile range, and frequency were used as descriptive statistics. IGF1 values were expressed as percentage of the upper limit of the normal range (\%ULN). The Fisher's exact test or the $\chi^{2}$-test were used to investigate dichotomic variables, while a two-sided $t$-test (or non-parametric test) was used to test continuous variables. A non-parametric Kruskal-Wallis test, followed by the Bonferroni post hoc test, was used for multiple comparisons among several groups for non-normal distributed variables. Correlations and 95\% CIs between the total number of mutations and different clinical parameters were evaluated by linear regression analysis. Statistical analyses were performed using the GraphPad Prism (version 5.0, La Jolla, CA, USA) and SPSS (PASW version 21.0, SPSS, Inc.) software. $P$ values $<0.05$ were considered as statistically significant.

\section{Results}

\section{Targeted DNA sequencing (Group 1)}

A total of 31 patients affected by GH-secreting adenomas were included in this group. Minimum clinical data were 
available for 17 of them (10 males and 7 females; median age: 46 years, range: 19-64; 16 macroadenomas and 1 microadenoma; median basal GH levels: $24.3 \mathrm{ng} / \mathrm{ml}$, range: 2.3-333; median IGF1 \%ULN: 391, range: 266-590).

We observed the presence of known activating GNAS mutations in five out of 31 evaluated samples $(16.1 \%$ of cases), i.e. a p.Arg201Cys substitution in four samples and a p.Gln227Leu in one sample. We did not identify any mutation in all the evaluated exons of PRKACA and USP8 (Table 1). However, we detected different polymorphisms in the USP8 gene: exon 1 (rs3131575 T/G heterozygous in eight cases and homozygous in one case, rs11632697 G/C heterozygous in 14 cases and homozygous in one case, and rs $11632708 \mathrm{C} / \mathrm{T}$ heterozygous in 13 cases and homozygous

Table 1 List of genetic alterations at targeted sequencing of $31 \mathrm{GH}$-secreting pituitary adenomas. PRKACA exons 7 and 8 and USP8 exons 2 and 3 showed no sequence variants and are not included.

\begin{tabular}{|c|c|}
\hline Tumor ID (Group 1) & GNAS \\
\hline $1-16$ & WT \\
\hline $1-18$ & WT \\
\hline $1-20$ & WT \\
\hline $1-24$ & WT \\
\hline $1-25$ & WT \\
\hline $1-26$ & WT \\
\hline $1-28$ & WT \\
\hline $1-29$ & WT \\
\hline $1-31$ & WT \\
\hline $1-32$ & WT \\
\hline $1-33$ & WT \\
\hline $1-35$ & WT \\
\hline $1-37$ & WT \\
\hline $1-38$ & WT \\
\hline $1-39$ & WT \\
\hline $1-40$ & p.Q227L heterozygous \\
\hline $1-43$ & WT \\
\hline $1-44$ & WT \\
\hline $1-46$ & WT \\
\hline $1-48$ & WT \\
\hline $1-50$ & p.R201C heterozygous \\
\hline $1-51$ & WT \\
\hline $1-52$ & WT \\
\hline $1-53$ & p.R201C heterozygous \\
\hline $1-54$ & p.R201C heterozygous \\
\hline $1-55$ & rs121913494 heterozygous \\
\hline $1-57$ & WT \\
\hline $1-58$ & p.R201C heterozygous \\
\hline $1-60$ & WT \\
\hline $1-61$ & WT \\
\hline $1-62$ & WT \\
\hline
\end{tabular}

USP8 Ex 1

rs3131575 heterozygous

rs11632697 heterozygous WT

rs11632697 heterozygous, rs11632708 heterozygous rs11632697 heterozygous,

rs11632708 heterozygous rs11632697 heterozygous, rs11632708 heterozygous WT

WT

WT

rs11632697 homozygous, rs11632708 homozygous rs11632697 heterozygous, rs11632708 heterozygous, rs3131575 heterozygous WT

rs11632697 heterozygous, rs11632708 heterozygous, rs3131575 heterozygous WT

rs11632697 heterozygous, rs11632708 heterozygous WT

WT

rs11632697 heterozygous, rs11632708 heterozygous rs3131575 heterozygous WT

rs11632697 heterozygous, rs11632708 heterozygous rs11632697 heterozygous, rs11632708 heterozygous WT

rs11632697 heterozygous, rs11632708 heterozygous WT

rs11632697 heterozygous, rs11632708 heterozygous, rs3131575 heterozygous rs3131575 heterozygous rs11632697 heterozygous, rs11632708 heterozygous, rs3131575 heterozygous

rs3131575 homozygous rs3131575 heterozygous WT
USP8 14-3-3 domain

WT

rs11638390 heterozygous WT

rs11638390 heterozygous

rs11638390 heterozygous

rs11638390 heterozygous

WT

WT

WT

rs11638390 homozygous

rs11638390 heterozygous

WT

rs11638390 heterozygous

WT

rs11638390 heterozygous

WT

WT

rs11638390 heterozygous

WT

WT

rs11638390 heterozygous

rs11638390 heterozygous

rs11638390 heterozygous rs11638390 heterozygous

WT

rs11638390 heterozygous

WT

rs11638390 heterozygous

WT

WT

WT 
Table 2 Clinical and genetic data of the 36 patients affected by GH-secreting pituitary adenomas evaluated by next-generation exome-sequencing (Group 2).

\begin{tabular}{|c|c|c|c|c|c|}
\hline & All & No mutations & $\begin{array}{l}\text { Low number } \\
\text { of mutation } \\
\qquad(\leq \mathbf{3})\end{array}$ & $\begin{array}{l}\text { High number } \\
\text { of mutations } \\
\qquad(>3)\end{array}$ & $\boldsymbol{P}$ \\
\hline \multicolumn{6}{|l|}{ Clinical data at the time of diagnosis ${ }^{a}$} \\
\hline$n$ & 36 & 5 & 14 & 17 & - \\
\hline $\operatorname{Sex}(M / F)$ & $16 / 18$ & $1 / 4$ & $6 / 6$ & $8 / 9$ & NS \\
\hline Age (years) & $47.8 \pm 19.0$ & $32.4 \pm 28.0$ & $44.2 \pm 7.0$ & $54.1 \pm 17.5$ & NS \\
\hline Tumor size $(\mathrm{mm})$ & $18.8 \pm 9 ., 6$ & $13.0 \pm 3.5$ & $20.6 \pm 10.0$ & $19.2 \pm 11.2$ & NS \\
\hline Micro/MACRO & $2 / 32$ & $1 / \overline{4}$ & $1 / 11$ & $1 / 16$ & NS \\
\hline \multicolumn{6}{|l|}{ GH levels $(\mu \mathrm{g} / \mathrm{l})$} \\
\hline Basal & $24.3 \pm 27 ., 9$ & $50.4 \pm 58.5$ & $29.7 \pm 28.2$ & $18.2 \pm 14.4$ & NS \\
\hline Post-OGTT nadir & $21.6 \pm 20 ., 8$ & $15.2 \pm 16.0$ & $29.7 \pm 31.9$ & $20.3 \pm 18.9$ & NS \\
\hline IGF1 levels (\%UNL) & $334 \pm 152$ & $312 \pm 165$ & $282 \pm 122$ & $372 \pm 158$ & NS \\
\hline Pituitary deficiencies (yes/no) & $5 / 29$ & $0 / 5$ & $4 / 8$ & $1 / 16$ & 0.07 \\
\hline Co-secretion with prolactin (yes/no) & $7 / 27$ & $1 / 4$ & $1 / 11$ & $5 / 12$ & NS \\
\hline Diabetes (yes/no) & $10 / 22$ & $1 / 4$ & $3 / 9$ & $6 / 11$ & NS \\
\hline Hypertension (yes/no) & $10 / 22$ & $1 / 4$ & $3 / 9$ & $6 / 11$ & NS \\
\hline Cardiac disease (yes/no) & $3 / 29$ & $0 / 5$ & $1 / 11$ & $2 / 15$ & NS \\
\hline \multicolumn{6}{|l|}{ Clinical data after surgery } \\
\hline Additional radiotherapy (yes/no) & $3 / 27$ & $0 / 5$ & $0 / 12$ & $3 / 12$ & NS \\
\hline Additional drug therapy (yes/no) & $9 / 19$ & $3 / 2$ & $4 / 8$ & $2 / 9$ & NS \\
\hline Biochemical remission (yes/no) ${ }^{\mathrm{b}}$ & $9 / 7$ & $1 / 3$ & $5 / 2$ & $3 / 4$ & NS \\
\hline \multicolumn{6}{|l|}{ Genetic data } \\
\hline Total number of mutations & 175 & 0 & $1.6 \pm 0.9$ & $6.3 \pm 3.1$ & $<0.001$ \\
\hline GNAS mutations $(n-\%)$ & $11(29.7 \%)$ & 0 & $5(35.7 \%)$ & $6(33 \%)$ & NS \\
\hline
\end{tabular}

M, male; F, female; micro, microadenoma; MACRO, macroadenoma; OGTT, oral glucose tolerance test; and \%ULN, percentage of the upper normal limit.

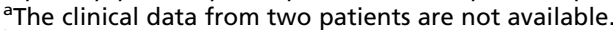

${ }^{b}$ Biochemical remission evaluated 3-6 months after surgery.

in one case) and 14-3-3 binding domain (rs11638390 A/G heterozygous p.T739A in 14 cases and homozygous in one case) (Table 1). Allele frequencies did not differ significantly from frequencies reported in dbSNP database (http://www.ncbi.nlm.nih.gov/SNP/) (Supplementary Table 2, see section on supplementary data given at the end of this article).

\section{Next-generation exome sequencing (Group 2)}

The histopathological and clinical parameters for the patients included in this analysis are reported in the Table 2. At the whole-exome sequencing, we identified a total of 132 protein-altering somatic mutations in 36 samples, resulting in a median of three somatic mutations in exonic regions per sample (range: 0-13). The genetic alterations included 109 missense and seven nonsense mutations, 12 frameshift, two direct splicing, and two indel variations. According to the PolyPhen-2, 39 mutations were classified as probably damaging, 25 as possibly damaging, and 41 as benign. The entire list of the somatic

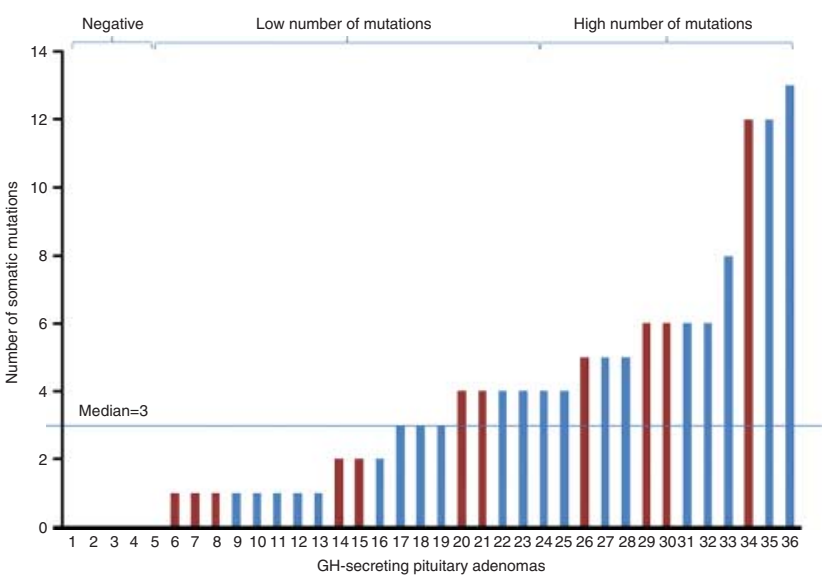

Figure 1

Total number of somatic mutations in the $36 \mathrm{GH}$-secreting pituitary tumors evaluated by next-generation exome sequencing (Group 2). The tumors affected by mutations in GNAS are represented with red bars. The numeration of the $\mathrm{GH}$-secreting adenomas is consecutive and do not correspond to the tumor identification number. 
mutations including localization, gene symbols, and transcripts is reported in the Supplementary Table 3, see section on supplementary data given at the end of this article.

We identified a subgroup of patients without any mutation (negative, $n=5$ ), a subgroup with a low number of mutations ( $n 1-3 ; n=14)$, and a subgroup with a high number of mutations ( $n>3 ; n=17)$ (Fig. 1). No significant correlation was observed between the total number of mutations and the evaluated clinical data, such as sex, age, tumor size and extension, and the initial GH levels.

The most frequent genetic alterations were the known gain-of-function mutations in the GNAS gene. Specifically, they were detected in 11 cases (31.4\% of total, ten of them being females), encoding p.Arg201Cys substitution in seven samples, p.Arg201His in two samples, and p.Gln227Leu in two samples. No difference was observed in total number of mutations between the tumors with or without GNAS mutations (Fig. 1). No further genetic alterations were found in more than one sample in this series. Even comparing the list of the mutated genes with that of a recent paper on whole-genome sequencing in
12 GH-secreting adenomas (37), no additional recurrent somatic genetic alterations were observed.

However, some non-recurrent heterozygous somatic variants were observed in genes encoding GPCR, such as the chemokine receptor 10 (CCR10) and the olfactory receptor OR51B4, which are coupled to the Gs protein (activation of the cAMP signaling pathway), and the M3 muscarinic cholinergic receptor (CHRM3), which functions through Gq (activation of the inositol trisphosphate/calcium signaling pathway). Moreover, other nonrecurrent alterations were found in genes coding for proteins involved in cAMP signaling pathway other than GNAS, such as the $\alpha 2$ catalytic subunit of the AMPactivated protein kinase (PRKAA2), the G-protein-coupled receptor kinase 3 (GRK3, alias $A D R B K 2)$, and the A1 subunit of the lysosomal $\mathrm{H}^{+}$ATPase (ATP6VOA1). Taken together, the mutations in genes involved in the cAMP signaling affected $14 / 36$ samples (38.9\% of total). Among them, nine samples presented only GNAS mutations, two samples mutations at GNAS and other genes of the cAMP signaling and three only mutations in other genes

Table 3 List of somatic mutations in genes associated with the cAMP signaling pathway or in the calcium signaling/metabolism detected in $36 \mathrm{GH}$-secreting pituitary adenomas (Group 2; the RefSeq annotation does not provide any annotated transcript for the position chr6:119532096, corresponding ENSEMBL identification 'ENST00000368466').

\begin{tabular}{l} 
Gene symbol \\
\hline CAMP signaling path \\
GNAS \\
PRKAA2 \\
ADRBK2 \\
ATP6V0A1 \\
CCR10 \\
CHRM3 \\
OR51B4 \\
Calcium signaling \\
CACNA1H \\
CAPN1 \\
DMD \\
GRIN2B \\
JPH2 \\
MAN1A1 \\
PCDH11X \\
PROCA1 \\
SLIT2 \\
SPTA1 \\
TESC \\
\end{tabular}

NA, not applicable.

*Corresponds to non-sense mutations according to the HVGS recommendations.

\begin{tabular}{|c|c|c|}
\hline Base change & Protein change & $\begin{array}{l}\text { Number of } \\
\text { samples }\end{array}$ \\
\hline c. $601 \mathrm{C}>\mathrm{T}$ & p.Arg201Cys & 7 \\
\hline c. $602 \mathrm{G}>\mathrm{A}$ & p.Arg $201 \mathrm{His}$ & 2 \\
\hline c. $584 \mathrm{~A}>\mathrm{T}$ & p. GIn227Leu & 2 \\
\hline C. $1132 C>G$ & p.Pro378Ala & 1 \\
\hline c. $1976 \mathrm{G}>\mathrm{A}$ & p.Arg659His & 1 \\
\hline c. $94 \mathrm{C}>\mathrm{A}$ & p.Leu32Ile & 1 \\
\hline c. $691 \mathrm{C}>\mathrm{T}$ & p.Gly231Ser & 1 \\
\hline c. $1244 A>G$ & p.Asp415Gly & 1 \\
\hline c.619C-> T & p.Asp207Asn & 1 \\
\hline c. $1175 C>T$ & p.Ser392Leu & 1 \\
\hline c. $380 A>G$ & p.Asn127Ser & 1 \\
\hline c. $960 \mathrm{G}>\mathrm{C}$ & p.Ser320Arg & 1 \\
\hline c. $1894 C>A$ & p.Val632Leu & 1 \\
\hline c. $1111 C>A$ & p.Glu371* & 1 \\
\hline c. $A G>>A A$ & NA & 1 \\
\hline c. $3725 C>G$ & p.Ala1242Gly & 1 \\
\hline c. $749 C>G$ & p.Arg250Pro & 1 \\
\hline c. $4190 \mathrm{G}>\mathrm{A}$ & p.Cys139Tyr & 1 \\
\hline c. $7201 G>A$ & p.Arg2401* & 1 \\
\hline $\begin{array}{l}\text { 10_16delAGTGGGC, } \\
\text { frameshift, } 117537071\end{array}$ & & 1 \\
\hline
\end{tabular}




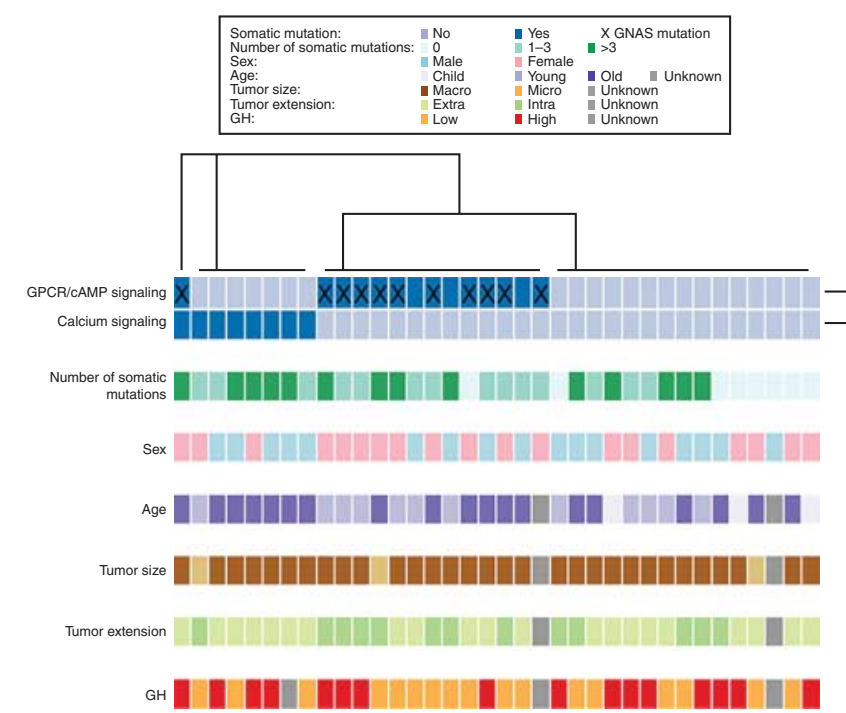

Figure 2

Overview of the somatic mutations at genes involved in the CAMP signaling (i.e., CCR10, OR51B4, CHRM3, GNAS, PRKAA2, GRK3, and ATP6V0A1) or in the calcium signaling (i.e., CACNA1H, CAPN1, DMD, GRIN2B, JPH2, MAN1A1, PCDH11X, PROCA1, SLIT2, SPTA1, TESC) in GH-secreting adenomas evaluated by next-generation exome sequencing $(n=36)$ and relationship with the total number of somatic mutations, sex, basal GH levels, and tumor extension at the time of diagnosis. Age: child $<18$ years, young $\leq 50$ years (median), old $>50$ years; tumor size: macro $=$ macroadenoma and micro $=$ microadenoma; tumor extension: extra $=$ extrasellar and intra $=$ intrasellar; and GH: low $\leq 15 \mu \mathrm{g} / \mathrm{l}$ (median) and high $>15 \mu \mathrm{g} / \mathrm{l}$.

encoding GPCR or other members of the cAMP signaling. The corresponding details are reported in the Table 3.

Finally, a number of altered genes associated at different levels with the $\mathrm{Ca}^{2+}$ signaling and metabolism (i.e., involving both extra and intracellular compartment) were observed in eight cases $(22.2 \%$ of total). They consisted in the $\alpha 1 \mathrm{H}$ subunit of the voltage-dependent $\mathrm{T}$ type calcium channel (CACNA1H), the large subunit of the calpain 1 (CAPN1), the dystrophin (DMD), the NMDA ionotropic glutamate receptor $2 \mathrm{~B}$ (GRIN2B), the junctophilin 2 (JPH2), the mannosidase $\alpha$ class $1 \mathrm{~A}$ (MAN1A1), the $\mathrm{X}$-linked protocadherin 11 (PCDH11X), the protein interacting with cyclin A1 (PROCA1), the slit homolog 2 (SLIT2), the erythroid $\alpha 1$ spectrin (SPTA1), and the tescalcin (TESC) (Table 3).

An unsupervised clustering including all the somatic mutations in genes involved in the cAMP pathway or in the $\mathrm{Ca}^{2+}$ signaling was performed. The results including the relationship with the total number of somatic mutations and clinical data are shown in the Fig. 2.

Concerning the correlation with the clinical data, the patients with mutations in genes of the cAMP signaling pathway were mostly females $(10 / 14,71 \%)$, while those with mutations in genes associated with the $\mathrm{Ca}^{2+}$ signaling were mostly males $(5 / 7,71 \%)$ and those with other kinds of mutations were equally distributed between the two sexes $(50 \%, P<0.001$ by Kruskal-Wallis test for multiple comparisons) (Figs 2 and 3). A trend to a lower total number of mutations and younger age was observed in the group of patients without alterations of the cAMP or $\mathrm{Ca}^{2+}$ signaling in comparison with the other two groups (Figs 2 and 3). No significant differences in terms of tumor size and basal GH or IGF1 levels have been found.

Functional annotation and pathway analysis $>$ The gene enrichment analysis in the entire series identified a total of 117 altered genes associated with a gene ontology term. Several altered genes resulted to be associated with developmental biological processes (Supplementary Table 4 , see section on supplementary data given at the end of this article). The canonical pathway analysis recognized no significant overlaps. The gene family analysis showed the presence of one cytokine/growth factor (SLIT2), seven protein kinases (ADRBK2, CDK10,

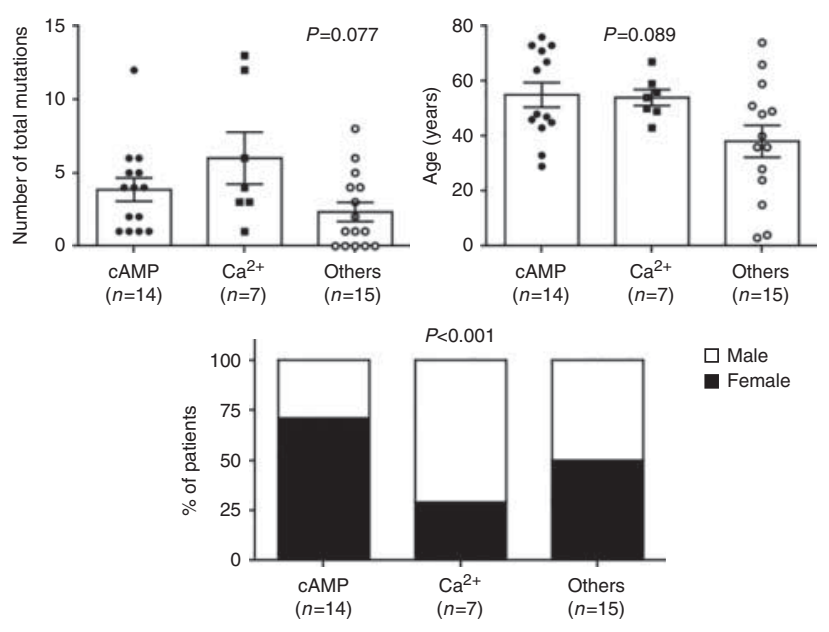

\section{Figure 3}

Relationship between the genetic alterations observed at the exome sequencing (i.e. mutations in genes member of the CAMP pathway, of the calcium signaling or in others) and clinical data (i.e. total number of somatic mutations in upper panel, age in the middle panel, and sex in the lower panel) in 36 evaluated $\mathrm{GH}$-secreting adenomas. 
CHUK, EPHA8, PRKAA2, SCYL1, and TESK1), four known oncogenes (GNAS, KDM5A,SH3GL1, and STIL) and two tumor suppressor genes (SETD2 and TSC2) among the mutated genes.

\section{Discussion}

The present study offers a comprehensive genetic characterization of a large cohort of $67 \mathrm{GH}$-secreting pituitary adenomas. We aimed to identify novel molecular markers potentially involved in tumorigenesis and/or in clinical outcome. To this end, we first performed targeted sequencing of GNAS, PRKACA, and USP8 genes in order to evaluate the presence of mutations in these genes in GH-secreting adenomas, finding only known GNAS gene mutations. By whole-exome sequencing, only a limited number of genetic alterations have been detected in the 36 evaluated samples. This finding is consistent with the low mitotic activity of pituitary tumors and with previous small studies on both non-functioning $(n=7)$ (43) and GH-secreting pituitary adenomas $(n=12)$ (37). Moreover, no recurrent somatic mutations have been observed, except the known alterations at the GNAS gene, similarly to a previous report on a small series of GH-secreting adenomas (37). In particular, no somatic mutations have been also detected at the gene GPR101, probably due to the low reported frequency of this mutations (11/248 cases) (33), and, at both the exome sequencing and the targeted sequencing, we did not find any mutations of the PRKACA and USP8 genes. These findings further confirm that both these genetic alterations are not involved in the pathogenesis of GH-secreting adenomas $(32,36)$.

Interestingly, several non-recurrent alterations affected other genes involved in the cAMP signaling besides GNAS (see Table 2). These findings further support the view that deregulation of cAMP pathway is the most important pathogenetic mechanism in GH-secreting adenomas. Furthermore, a number of genes associated with the $\mathrm{Ca}^{2+}$ signaling (see Table 2) were altered. These findings are in agreement with another recent study on whole-genome alterations in $12 \mathrm{GH}$-secreting adenomas (37). This is consistent with the notion that binding of growth hormone-releasing hormone to its receptor activates not only the stimulatory subunit $\alpha$ of the G-protein (G $\alpha$-S, cAMP-dependent pathways) but also G $\alpha$-I, G $\beta$, and $\mathrm{G} \gamma$, leading to release of intracellular free $\mathrm{Ca}^{2+}$, which then further triggers secretion of $\mathrm{GH}(44,45)$. Moreover, ATP, which is co-released with pituitary hormones, induces an increase in free $\mathrm{Ca}^{2+}$ in pituitary cells (46). These data strongly suggest that dysregulation of the calcium signaling might be an important co-signal in somatotrophs and potentially involved in pituitary tumorigenesis. However, its biological role needs to be better investigated in future functional studies.

It has been suggested that tumors might be very heterogeneous with few mutations in common. Instead, different genes acting through the same molecular pathways may contribute to tumor formation (47). Therefore, it is possible that at least some of these low-frequency GH-secreting tumor variants present tumor-promoting mutations. Alternatively, they may present other types of molecular alterations not detectable by exome sequencing (i.e., mutations in non-coding intronic chromosomal regions).

In conclusion, we found no novel recurrently mutated genes in a large series of GH-secreting pituitary adenomas. However, our and previous genetic findings suggest that beside cAMP pathway, also different pathways, such as $\mathrm{Ca}^{2+}$ signaling, may play an important role in the pathogenesis of these tumors.

\section{Supplementary data}

This is linked to the online version of the paper at http://dx.doi.org/10.1530/ EJE-15-1064.

\section{Declaration of interest}

The authors declare that there is no conflict of interest that could be perceived as prejudicing the impartiality of the research reported.

\section{Funding}

The study was supported by grants IZKF Wuerzburg (B-281 to D Calebiro and M Fassnacht), by the ERA-NET 'E-Rare' (01GM1407B to M Fassnacht) and by the Associazione Italiana Ricerca Cancro, Milan (AIRC) (IG-15 507 to G Mantovani).

Author contribution statement

C L Ronchi, B Allolio, M Reincke and M Fassnacht conceived the idea of the study. C L Ronchi developed the protocol of the study, coordinated the collection of the tissue materials and the clinical data, performed the statistical analysis, and wrote the first draft of the paper; E Peverelli, G Mantovani, and A Spada, provided the tumor tissue and the corresponding blood samples and contributed to wrote the paper; $S$ Herterich performed the targeted sequencing analysis; I Weigand, D Calebiro, and S Sbiera contributed to the protocol of the study and to the data analysis; S Appenzeller performed the clustering and the heatmap; J Honegger, M Reincke, M Buchfelder, and J Flitsch provided the tumor tissue and the corresponding blood samples; T M Strom performed the whole-exome sequencing analysis including the filtering and the first data analysis; and M Fassnacht contributed to the coordination of the study and to write the paper. All the authors reviewed and approved the final version of the manuscript. 
Acknowledgements

The authors are grateful to Mrs Michaela Bekteshi for expert technical support.

\section{References}

1 Chanson P, Salenave S, Kamenicky P, Cazabat L \& Young J. Pituitary tumours: acromegaly. Best Practice \& Research 200923 555-574. (doi:10.1016/j.beem.2009.05.010)

2 Sherlock M, Ayuk J, Tomlinson JW, Toogood AA, Aragon-Alonso A, Sheppard MC, Bates AS \& Stewart PM. Mortality in patients with pituitary disease. Endocrine Reviews 201031 301-342. (doi:10.1210/er. 2009-0033)

3 Melmed S, Kleinberg DL, Bonert V \& Fleseriu M. Acromegaly: assessing the disorder and navigating therapeutic options for treatment. Endocrine Practice 201420 (Suppl 1) 7-17 quiz 18-20. (doi:10.4158/ EP14430.RA)

4 Asa SL \& Ezzat S. The pathogenesis of pituitary tumours. Nature Reviews Cancer 20022 836-849. (doi:10.1038/nrc926)

5 Clayton RN \& Farrell WE. Pituitary tumour clonality revisited. Frontiers of Hormone Research 200432 186-204.

6 Vallar L, Spada A \& Giannattasio G. Altered Gs and adenylate cyclase activity in human GH-secreting pituitary adenomas. Nature 1987330 566-568. (doi:10.1038/330566a0)

7 Landis CA, Masters SB, Spada A, Pace AM, Bourne HR \& Vallar L. GTPase inhibiting mutations activate the alpha chain of Gs and stimulate adenylyl cyclase in human pituitary tumours. Nature 1989340 692-696. (doi:10.1038/340692a0)

8 Landis CA, Harsh G, Lyons J, Davis RL, McCormick F \& Bourne HR. Clinical characteristics of acromegalic patients whose pituitary tumors contain mutant Gs protein. Journal of Clinical Endocrinology and Metabolism 199071 1416-1420. (doi:10.1210/jcem-71-6-1416)

9 Clementi E, Malgaretti N, Meldolesi J \& Taramelli R. A new constitutively activating mutation of the Gs protein alpha subunit-gsp oncogene is found in human pituitary tumours. Oncogene 19905 1059-1061.

10 Lania AG, Mantovani G, Ferrero S, Pellegrini C, Bondioni S, Peverelli E, Braidotti P, Locatelli M, Zavanone ML, Ferrante E et al. Proliferation of transformed somatotroph cells related to low or absent expression of protein kinase a regulatory subunit 1A protein. Cancer Research 200464 9193-9198. (doi:10.1158/0008-5472.CAN-04-1847)

11 Vitali E, Peverelli E, Giardino E, Locatelli M, Lasio GB, Beck-Peccoz P, Spada A, Lania AG \& Mantovani G. Cyclic adenosine $3^{\prime}-5^{\prime}$-monophosphate (cAMP) exerts proliferative and anti-proliferative effects in pituitary cells of different types by activating both cAMP-dependent protein kinase A (PKA) and exchange proteins directly activated by cAMP (Epac). Molecular and Cellular Endocrinology 2014383 193-202. (doi:10.1016/j.mce.2013.12.006)

12 Hayward BE, Barlier A, Korbonits M, Grossman AB, Jacquet P, Enjalbert A \& Bonthron DT. Imprinting of the G(s)alpha gene GNAS1 in the pathogenesis of acromegaly. Journal of Clinical Investigation 2001 107 R31-R36. (doi:10.1172/JCI11887)

13 Mantovani G, Ballare E, Giammona E, Beck-Peccoz P \& Spada A. The gsalpha gene: predominant maternal origin of transcription in human thyroid gland and gonads. Journal of Clinical Endocrinology and Metabolism 200287 4736-4740. (doi:10.1210/jc.2002-020183)

14 Mantovani G, Bondioni S, Lania AG, Corbetta S, de Sanctis L, Cappa M, Di Battista E, Chanson P, Beck-Peccoz P \& Spada A. Parental origin of Gsalpha mutations in the McCune-Albright syndrome and in isolated endocrine tumors. Journal of Clinical Endocrinology and Metabolism 2004 89 3007-3009. (doi:10.1210/jc.2004-0194)

15 Picard C, Silvy M, Gerard C, Buffat C, Lavaque E, Figarella-Branger D, Dufour H, Gabert J, Beckers A, Brue T et al. Gs alpha overexpression and loss of Gs alpha imprinting in human somatotroph adenomas: association with tumor size and response to pharmacologic treatment. International Journal of Cancer 2007121 1245-1252. (doi:10.1002/ijc. 22816)

16 Petersenn S, Heyens M, Ludecke DK, Beil FU \& Schulte HM. Absence of somatostatin receptor type 2 A mutations and gip oncogene in pituitary somatotroph adenomas. Clinical Endocrinology 200052 35-42. (doi:10.1046/j.1365-2265.2000.00880.x)

17 Dong Q, Brucker-Davis F, Weintraub BD, Smallridge RC, Carr FE, Battey J, Spiegel AM \& Shenker A. Screening of candidate oncogenes in human thyrotroph tumors: absence of activating mutations of the G alpha q, G alpha 11, G alpha s, or thyrotropin-releasing hormone receptor genes. Journal of Clinical Endocrinology and Metabolism $1996 \mathbf{8 1}$ 1134-1140. (doi:10.1210/jcem.81.3.8772588)

18 Farrell WE, Talbot JA, Bicknell EJ, Simpson D \& Clayton RN. Genomic sequence analysis of a key residue (Arg183) in human G alpha q in invasive non-functional pituitary adenomas. Clinical Endocrinology 199747 241-244. (doi:10.1046/j.1365-2265.1997.2891088.x)

19 Pack SD, Kirschner LS, Pak E, Zhuang Z, Carney JA \& Stratakis CA. Genetic and histologic studies of somatomammotropic pituitary tumors in patients with the "complex of spotty skin pigmentation, myxomas, endocrine overactivity and schwannomas" (Carney complex). Journal of Clinical Endocrinology and Metabolism 200085 3860-3865. (doi:10.1210/jcem.85.10.6875)

20 Kirschner LS, Carney JA, Pack SD, Taymans SE, Giatzakis C, Cho YS, Cho-Chung YS \& Stratakis CA. Mutations of the gene encoding the protein kinase A type I-alpha regulatory subunit in patients with the Carney complex. Nature Genetics 200026 89-92. (doi:10.1038/79238)

21 Yamasaki H, Mizusawa N, Nagahiro S, Yamada S, Sano T, Itakura M \& Yoshimoto K. GH-secreting pituitary adenomas infrequently contain inactivating mutations of PRKAR1A and LOH of 17q23-24 Clinical Endocrinology 200358 464-470. (doi:10.1046/j.1365-2265. 2003.01740.x)

22 Sandrini F, Kirschner LS, Bei T, Farmakidis C, Yasufuku-Takano J, Takano K, Prezant TR, Marx SJ, Farrell WE, Clayton RN et al. PRKAR1A, one of the Carney complex genes, and its locus (17q22-24) are rarely altered in pituitary tumours outside the Carney complex. Journal of Medical Genetics 200239 e78. (doi:10.1136/jmg.39.12.e78)

23 Horvath A, Mathyakina L, Vong Q, Baxendale V, Pang AL, Chan WY \& Stratakis CA. Serial analysis of gene expression in adrenocortical hyperplasia caused by a germline PRKAR1A mutation. Journal of Clinical Endocrinology and Metabolism 200691 584-596. (doi:10.1210/jc. 2005-1301)

24 Horvath A, Boikos S, Giatzakis C, Robinson-White A, Groussin L, Griffin KJ, Stein E, Levine E, Delimpasi G, Hsiao HP et al. A genome-wide scan identifies mutations in the gene encoding phosphodiesterase 11A4 (PDE11A) in individuals with adrenocortical hyperplasia. Nature Genetics 200638 794-800. (doi:10.1038/ng1809)

25 Peverelli E, Ermetici F, Filopanti M, Elli FM, Ronchi CL, Mantovani G, Ferrero S, Bosari S, Beck-Peccoz P, Lania A et al. Analysis of genetic variants of phosphodiesterase $11 \mathrm{~A}$ in acromegalic patients. European Journal of Endocrinology 2009161 687-694. (doi:10.1530/EJE-09-0677)

26 Beuschlein F, Fassnacht M, Assie G, Calebiro D, Stratakis CA, Osswald A, Ronchi CL, Wieland T, Sbiera S, Faucz FR et al. Constitutive activation of PKA catalytic subunit in adrenal Cushing's syndrome. New England Journal of Medicine 2014370 1019-1028. (doi:10.1056/ NEJMoa1310359)

27 Cao Y, He M, Gao Z, Peng Y, Li Y, Li L, Zhou W, Li X, Zhong X, Lei Y et al. Activating hotspot L205R mutation in PRKACA and adrenal Cushing's syndrome. Science 2014344 913-917. (doi:10.1126/science. 1249480)

28 Sato Y, Maekawa S, Ishii R, Sanada M, Morikawa T, Shiraishi Y, Yoshida K, Nagata Y, Sato-Otsubo A, Yoshizato T et al. Recurrent somatic mutations underlie corticotropin-independent Cushing's syndrome. Science 2014344 917-920. (doi:10.1126/science.1252328) 
29 Goh G, Scholl UI, Healy JM, Choi M, Prasad ML, Nelson-Williams C, Kunstman JW, Korah R, Suttorp AC, Dietrich D et al. Recurrent activating mutation in PRKACA in cortisol-producing adrenal tumors. Nature Genetics 201446 613-617. (doi:10.1038/ng.2956)

30 Di Dalmazi G, Kisker C, Calebiro D, Mannelli M, Canu L, Arnaldi G, Quinkler M, Rayes N, Tabarin A, Laure Jullie M et al. Novel somatic mutations in the catalytic subunit of the protein kinase A as a cause of adrenal Cushing's syndrome: a European multicentric study. Journal of Clinical Endocrinology and Metabolism 201499 E2093-E2100. (doi:10.1210/jc.2014-2152)

31 Calebiro D, Hannawacker A, Lyga S, Bathon K, Zabel U, Ronchi C, Beuschlein F, Reincke M, Lorenz K, Allolio B et al. PKA catalytic subunit mutations in adrenocortical Cushing's adenoma impair association with the regulatory subunit. Nature Communications 201455680. (doi:10.1038/ncomms6680)

32 Larkin SJ, Ferrau F, Karavitaki N, Hernandez-Ramirez LC, Ansorge O, Grossman AB \& Korbonits M. Sequence analysis of the catalytic subunit of PKA in somatotroph adenomas. European Journal of Endocrinology 2014171 705-710. (doi:10.1530/EJE-14-0545)

33 Trivellin G, Daly AF, Faucz FR, Yuan B, Rostomyan L, Larco DO, Schernthaner-Reiter MH, Szarek E, Leal LF, Caberg JH et al. Gigantism and acromegaly due to Xq26 microduplications and GPR101 mutation. New England Journal of Medicine 2014371 2363-2374. (doi:10.1056/ NEJMoa1408028)

34 LeRiche VK, Asa SL \& Ezzat S. Epidermal growth factor and its receptor (EGF-R) in human pituitary adenomas: EGF-R correlates with tumor aggressiveness. Journal of Clinical Endocrinology and Metabolism $1996 \mathbf{8 1}$ 656-662. (doi:10.1210/jcem.81.2.8636285)

35 Chaidarun SS, Eggo MC, Sheppard MC \& Stewart PM. Expression of epidermal growth factor (EGF), its receptor, and related oncoprotein (erbB-2) in human pituitary tumors and response to EGF in vitro. Endocrinology 1994135 2012-2021. (doi:10.1210/endo.135.5.7956924)

36 Reincke M, Sbiera S, Hayakawa A, Theodoropoulou M, Osswald A, Beuschlein F, Meitinger T, Mizuno-Yamasaki E, Kawaguchi K, Saeki Y et al. Mutations in the deubiquitinase gene USP8 cause Cushing's disease. Nature Genetics 201547 31-38. (doi:10.1038/ng.3166)

37 Valimaki N, Demir H, Pitkanen E, Kaasinen E, Karppinen A, Kivipelto L, Schalin-Jantti C, Aaltonen LA \& Karhu A. Whole-genome sequencing of growth hormone (GH)-secreting pituitary adenomas. Journal of Clinical Endocrinology and Metabolism 2015100 3918-3927. (doi:10.1210/ jc.2015-3129)
38 Ronchi CL, Leich E, Sbiera S, Weismann D, Rosenwald A, Allolio B \& Fassnacht $\mathrm{M}$. Single nucleotide polymorphism microarray analysis in cortisol-secreting adrenocortical adenomas identifies new candidate genes and pathways. Neoplasia 201214 206-218. (doi:10.1593/neo. 111758)

39 Untergasser A, Nijveen H, Rao X, Bisseling T, Geurts R \& Leunissen JA. Primer3Plus, an enhanced web interface to Primer3. Nucleic Acids Research 200735 W71-W74. (doi:10.1093/nar/gkm306)

40 Adzhubei IA, Schmidt S, Peshkin L, Ramensky VE, Gerasimova A, Bork P, Kondrashov AS \& Sunyaev SR. A method and server for predicting damaging missense mutations. Nature Methods 20107 248-249. (doi:10.1038/nmeth0410-248)

41 Kumar P, Henikoff S \& Ng PC. Predicting the effects of coding non-synonymous variants on protein function using the SIFT algorithm. Nature Protocols 20094 1073-1081. (doi:10.1038/nprot. 2009.86)

42 Subramanian A, Tamayo P, Mootha VK, Mukherjee S, Ebert BL, Gillette MA, Paulovich A, Pomeroy SL, Golub TR, Lander ES et al. Gene set enrichment analysis: a knowledge-based approach for interpreting genome-wide expression profiles. PNAS 2005102 15545-15550. (doi:10.1073/pnas.0506580102)

43 Newey PJ, Nesbit MA, Rimmer AJ, Head RA, Gorvin CM, Attar M, Gregory L, Wass JA, Buck D, Karavitaki N et al. Whole-exome sequencing studies of nonfunctioning pituitary adenomas. Journal of Clinical Endocrinology and Metabolism 201398 E796-E800. (doi:10.1210/jc.2012-4028)

44 Meier K, Knepel W \& Schofl C. Potassium depolarization elevates cytosolic free calcium concentration in rat anterior pituitary cells through 1,4-dihydropyridine-sensitive, omega-conotoxin-insensitive calcium channels. Endocrinology 1988122 2764-2770. (doi:10.1210/endo-122-6-2764)

45 Canny BJ, Rawlings SR \& Leong DA. Pituitary adenylate cyclaseactivating polypeptide specifically increases cytosolic calcium ion concentration in rat gonadotropes and somatotropes. Endocrinology 1992130 211-215. (doi:10.1210/endo.130.1.1727697)

46 Villalobos C, Alonso-Torre SR, Nunez L \& Garcia-Sancho J. Functional ATP receptors in rat anterior pituitary cells. American Journal of Physiology 1997273 C1963-C1971.

47 Wood LD, Parsons DW, Jones S, Lin J, Sjoblom T, Leary RJ, Shen D, Boca SM, Barber T, Ptak J et al. The genomic landscapes of human breast and colorectal cancers. Science 2007318 1108-1113. (doi:10.1126/ science.1145720)

Received 30 October 2015

Revised version received 18 December 2015

Accepted 22 December 2015 